\title{
PRIME - PRocess modelling in ImpleMEntation research: selecting a theoretical basis for interventions to change clinical practice Anne E Walker ${ }^{1}$, Jeremy Grimshaw ${ }^{2}$, Marie Johnston ${ }^{3}$, Nigel Pitts ${ }^{4}$, Nick Steen ${ }^{5}$ and Martin Eccles*5
}

Address: ${ }^{1}$ Health Services Research Unit, University of Aberdeen, Aberdeen, UK, ${ }^{2}$ Clinical Epidemiology Programme, Ottawa Health Research Institute, Ottawa, Canada, ${ }^{3}$ Department of Psychology, University of Aberdeen, Aberdeen, UK, ${ }^{4}$ Dental Health Services Research Unit, University of Dundee, Dundee, UK and ${ }^{5}$ Centre for Health Services Research, University of Newcastle upon Tyne, UK

Email: Anne E Walker - anne_walker@yahoo.com; Jeremy Grimshaw - jgrimshaw@ohri.ca; Marie Johnston - m.johnston@abdn.ac.uk; Nigel Pitts - n.b.pitts@dundee.ac.uk; Nick Steen - nick.steen@ncl.ac.uk; Martin Eccles* - martin.eccles@ncl.ac.uk

* Corresponding author

Published: 19 December 2003

BMC Health Services Research 2003, 3:22
Received: 18 September 2003

Accepted: 19 December 2003

This article is available from: http://www.biomedcentral.com/I472-6963/3/22

(c) 2003 Walker et al; licensee BioMed Central Ltd. This is an Open Access article: verbatim copying and redistribution of this article are permitted in all media for any purpose, provided this notice is preserved along with the article's original URL.

\begin{abstract}
Background: Biomedical research constantly produces new findings but these are not routinely translated into health care practice. One way to address this problem is to develop effective interventions to translate research findings into practice. Currently a range of empirical interventions are available and systematic reviews of these have demonstrated that there is no single best intervention. This evidence base is difficult to use in routine settings because it cannot identify which intervention is most likely to be effective (or cost effective) in a particular situation. We need to establish a scientific rationale for interventions. As clinical practice is a form of human behaviour, theories of human behaviour that have proved useful in other similar settings may provide a basis for developing a scientific rationale for the choice of interventions to translate research findings into clinical practice.
\end{abstract}

The objectives of the study are: to amplify and populate scientifically validated theories of behaviour with evidence from the experience of health professionals; to use this as a basis for developing predictive questionnaires using replicable methods; to identify which elements of the questionnaire (i.e., which theoretical constructs) predict clinical practice and distinguish between evidence compliant and non-compliant practice; and on the basis of these results, to identify variables (based on theoretical constructs) that might be prime targets for behaviour change interventions.

Methods: We will develop postal questionnaires measuring two motivational, three action and one stage theory to explore five behaviours with 800 general medical and 600 general dental practitioners. We will collect data on performance for each of the behaviours. The relationships between predictor variables (theoretical constructs) and outcome measures (data on performance) in each survey will be assessed using multiple regression analysis and structural equation modelling. In the final phase of the project, the findings from all surveys will be analysed simultaneously adopting a random effects approach to investigate whether the relationships between predictor variables and outcome measures are modified by behaviour, professional group or geographical location. 


\section{Background}

Clinical and health services research is continually producing new findings that may contribute to effective and efficient patient care. However, despite the considerable resources devoted to biomedical science, a consistent finding from the literature is that the transfer of research findings into practice is a slow and haphazard process. Reports of inappropriate care abound across different healthcare settings, countries and specialties. In the UK, these include: primary medical care, e.g. the management of hypertension [1]; the administration of secondary prophylactic drugs to patients surviving a myocardial infarction [2]; primary dental care, e.g., selection criteria for dental radiography [3]; and secondary care, e.g. the administration of thrombolysis to patients thought to have suffered a myocardial infarction [4]; the administration of secondary prophylactic drugs to patients surviving a myocardial infarction [5].

The recognition of the failure to translate research findings into practice has led the UK government to propose the introduction of clinical governance [6] to 'assure and improve clinical standards throughout the NHS. This includes action to ensure risks are avoided, adverse events are rapidly detected, openly investigated and lessons learned, good practice is rapidly disseminated and systems are in place to ensure continuous improvements in clinical care'. Active dissemination and implementation strategies to promote evidencebased health care will be needed to achieve the clinical effectiveness element of clinical governance if it is to achieve its potential [7].

\section{Implementation research}

Implementation research is the scientific study of methods to promote the uptake of research findings, and hence to reduce inappropriate care. It includes the study of influences on healthcare professionals' behaviour and interventions to enable them to use research findings more effectively. Over the past five years a considerable body of implementation research has developed $[8,9]$. This research demonstrates that multifaceted complex interventions can be effective, but provides little information to guide the choice, or optimise the components, of such complex interventions in practice. The UK Medical Research Council recently proposed a framework for the development and evaluation of complex interventions such as implementation strategies [10].

This recognised the need to establish the theoretical bases of interventions and undertake exploratory studies to choose and refine interventions. This would optimise interventions to be evaluated in definitive trials and increase understanding of the generalisability of the findings of such studies. The value of such a framework can be illustrated by the development of cognitive-behavioural therapy (CBT), a complex and effective set of interventions that is now widely used in clinical practice to treat psychological problems such as chronic anxiety or phobia [11]. CBT developed from learning theories originating in the early twentieth century [12]. It was modelled and refined in analogue studies and exploratory trials in the 1960s (e.g., [13]); with definitive randomised controlled trials being conducted in the 1970s (e.g., [14]) and long term implementation studies conducted over the last twenty years $[15,16]$. We now need to apply a similar framework in implementation research.

In order to minimise the number of costly 'real world' pragmatic implementation trials that need to be conducted, it is necessary to identify the 'active ingredients' in professional behaviour change. Interventions could be effective for two reasons: they may contain components that effectively overcome the specific barriers encountered in relation to a particular practice; or they may contain components that are always effective in changing practice. Hence, two approaches are necessary to identify the 'active ingredients' in implementation interventions. One is to develop an understanding of the factors underlying clinical practice, in order to identify what sorts of processes should be targeted in implementation interventions (process modelling). The other is to develop an understanding of how the interventions themselves work. This study is concerned with process modelling.

The overall aim of process modelling in implementation research is to explore relevant theory to ensure the best choice of interventions to optimise clinical practice. Ferlie and Shortell [17] have suggested four levels at which interventions to improve the quality of health care might operate: the individual health professional; health care groups or teams; organisations providing health care (e.g., NHS trusts); and the larger health care system or environment in which individual organizations are embedded. Different types of theory will be relevant to interventions at different levels, for example, psychological theories will be more relevant to interventions directed at individuals and teams, theories of organisational change will be more relevant to interventions directed at hospitals or trusts, and so on. A full scientific rationale for interventions to translate research findings into clinical practice requires exploration of theories relevant to each of these four levels. This study focuses on the individual health professional level and investigates psychological theories to explore factors that are associated with adherence to evidence-based health care. We have chosen to start this work at the individual level and using psychological theories for the following reasons.

Eighty percent of existing interventions used in implementation research focus on the individual practitioner 
(e.g., continuing medical education, educational outreach, audit and feedback, reminders) [18]. To date the research evaluating these interventions has been empirically driven and a scientific rationale for the choice of interventions has not been developed. Evaluations of interventions at the organisational level are relatively rare in comparison. A wide range of factors influence health care delivery, however, most theories of organisational change propose that their effects on clinical practice are mediated through the actions of individual practitioners [19]. Ultimately, it is the individual clinician who decides whether or not to prescribe an antibiotic for a particular patient. This application includes psychological theories that propose that the professional's perception of factors, such as resource constraints or organisational policy, are key determinants of their actions.

Patient preferences, patient views and the dynamics of the professional-patient consultation are important factors in health care delivery. The theories included in this application will allow us to measure the effects of the health care professional's perception of these factors on their practice. For example, our previous work using one of the theories has found that some GPs are more likely to prescribe an antibiotic if a patient specifically asks for one [20]. The problem of understanding why health professionals do or do not implement research findings is similar to finding out why people do or do not adopt a healthy lifestyle. This is an area which has been extensively investigated, and in which psychological theories have already demonstrated their value.

\section{Psychological theories and health professional practice} The theories included in this study have been chosen for three reasons.

1. They have all been rigorously evaluated in other settings.

2. They all explain behaviour in terms of factors that are amenable to change (e.g., beliefs, attitudes, self-confidence and actual or perceived external constraints). Some psychological factors are difficult or impossible to change (e.g., personality and intelligence), even though they may be important predictors of behaviour, and we have deliberately avoided theories that invoke these non-modifiable factors.

3. They all include non-volitional components, i.e., they assume that individuals do not always have complete control over their actions. Thus, they will allow us to examine the influence of individuals' perceptions of external factors, such as patient preferences or organisational barriers and facilitators, on their behaviour.
The relevant psychological theories in this area can be divided into three broad categories: motivational theories, action theories and stage of change theories [21] and are summarised in Table 1.

Motivational theories propose that motivation determines behaviour, and therefore the best predictors of behaviour are factors that predict or determine motivation (or intention). Action theories may include motivational elements, but postulate that other factors are necessary to predict behaviour. Stage theories propose that individuals are at different stages in the progress toward behaviour change (for example, a motivated stage is likely to occur before an action stage), and that predictors of behaviour may be different for individuals at different stages. In this study we will test the predictive power of theoretical constructs drawn from two motivational theories (social cognitive theory and the theory of planned behaviour), three action theories (operant conditioning, implementation intentions and Leventhal's self-regulation model of illness cognitions) and a stage theory approach (adapted from the transtheoretical model of behaviour change and the precaution adoption process model).

\section{Motivational theories: social cognitive theory}

Bandura's social cognitive theory [22] proposes that behaviour is determined by incentives (see operant conditioning below) and expectancies. Three kinds of expectancies are described in the theory: situation outcome expectancies, outcome expectancies and self-efficacy expectancies. Situation-outcome expectancies are beliefs about how events are connected (e.g., smoking is bad for your health). Outcome expectancies refer to beliefs about the consequences of performing a behaviour (e.g., if I stop smoking, I will put on weight). Self efficacy expectancies are beliefs about one's ability to perform the behaviour (e.g., I can stop smoking). All of these are seen to be important in health behaviours, but self-efficacy expectancies have been found to be the most important in empirical studies [23]. It has been successfully applied to a wide range of health behaviours, and is one of the most powerful and consistent predictors [24]. For this reason, we will include the self-efficacy construct as a predictor variable.

\section{Motivational theories: the theory of planned behaviour}

The theory of planned behaviour [25] proposes that the strength of an individual's intention (or motivation) to engage in a behaviour, and the degree of control they feel they have over that behaviour (perceived behavioural control) are the proximal determinants of engaging in it. The perceived behavioural control construct in the theory of planned behaviour is closely related to (and originates from) the concept of self-efficacy in social cognitive theory. Recent studies have suggested that it is a broader con- 
Table I: Theories and theoretical constructs

\begin{tabular}{lll}
\hline Category of theory & Theory & Theoretical constructs \\
\hline Motivational & Theory of planned behaviour & $\begin{array}{l}\text { Behavioural intention } \\
\text { Perceived behavioural control } \\
\text { Attitude towards the behaviour } \\
\text { Subjective norm }\end{array}$ \\
\cline { 2 - 3 } & Social cognitive theory & Self-efficacy \\
\hline Oction & $\begin{array}{l}\text { Anticipated consequences of the behaviour } \\
\text { Frequency of performing the behaviour in the past }\end{array}$ \\
\cline { 2 - 3 } & $\begin{array}{l}\text { Implementation intentions } \\
\text { Leventhal's self-regulation theory }\end{array}$ & $\begin{array}{l}\text { Perceived identity of the condition } \\
\text { Perceived cause of the condition } \\
\text { Perceived controllability of the condition } \\
\text { Perceived duration of condition } \\
\text { Perceived consequences of condition } \\
\text { Emotional response to the condition }\end{array}$ \\
\hline Stage of change & \begin{tabular}{l} 
Current stage of change \\
\hline
\end{tabular}
\end{tabular}

struct, however, and is a proxy measure of the degree of actual control that people have over their behaviour as well as their confidence in performing it $[26,27]$. The theory of planned behaviour also includes propositions about the determinants of intention strength. It proposes that intention strength is determined by three variables: attitudes towards the behaviour, subjective norms and perceived behavioural control over it. These variables in turn are based upon salient beliefs about the behaviour.

Attitudes towards the behaviour are proposed to arise from a combination of beliefs about its consequences (behavioural beliefs - conceptually similar to outcome expectancies in social cognitive theory) and evaluations of those consequences (outcome evaluations). Subjective norms are based on perceptions of the views of other individuals or groups (normative beliefs), and the strength of the individual's desire to gain approval of these groups (motivation to comply). Influential people might include members of the clinical team, senior staff, patients, managers and professional organisations. Perceived behavioural control is a function of beliefs about factors likely to facilitate or inhibit the behaviour (control beliefs). These might include organisational constraints and patient preferences. This theory also proposes that attitude, subjective norm and perceived behavioural control have determinants. The attitude component is a function of people's beliefs about the outcome of the behaviour combined with their evaluation of these outcomes (similar to outcome expectancies in social cognitive theory).
The subjective norm component is a function of beliefs about the preferences of other salient groups or individuals, multiplied by the person's motivation to comply with this reference group. Perceived behavioural control is determined by beliefs about the potential barriers and facilitators to performing the behaviour, multiplied by the perceived power of these factors to inhibit or facilitate the behaviour. It is by measuring these beliefs that the theory of planned behaviour becomes sensitive to factors such as patient preferences or resource constraints on health professional practice. The four proximal determinants of behaviour from the theory of planned behaviour will be included as theoretical constructs (i.e., behavioural intention, attitude, subjective norm, perceived behavioural control). Determinants of attitude, subjective norm and perceived behavioural control will also be measured. These will only be included as predictor variables for the behavioural outcomes in the final analysis however if preliminary analysis shows that their effects on behavioural intention are not mediated by attitude, subjective norm and perceived behavioural control respectively.

\section{Action theories: operant conditioning}

Operant conditioning proposes that behaviours that have perceived positive consequences for the individual (such as remuneration) are likely to be repeated, whereas those that have perceived unpleasant consequences will become less frequent [28]. This is equivalent to the concept of incentives in social cognitive theory. An incentive is a perceived positive consequence of a behaviour. It can take a 
variety of forms, from material incentives (e.g., financial rewards), through social incentives (e.g., maintaining a positive relationship) to personal incentives (e.g., achieving a desired goal). The principle that positive consequences promote repetition of behaviour is well established and has been widely and successfully used to understand behaviour and behaviour change [29]. As rewarded behaviours are repeated, and may become 'habitual', the frequency of past behaviour can be a powerful predictor of future behaviour [30]. We will include two theoretical constructs derived from operant conditioning theory: perceived consequences of behaviour and frequency of behaviour in the past.

\section{Action theories: implementation intentions}

Gollwitzer [31] has made the distinction between goal intentions' and 'implementation intentions'. A goal intention is an intention to perform a behaviour or achieve a goal (e.g., I intend to reduce the number of referrals I make for lumbar spine x-rays). This is conceptually close to the behavioural intention construct in the theory of planned behaviour. By contrast, 'implementation intentions' are explicit plans about when and where a goal intention will be achieved [31]. Gollwitzer argues that by creating an implementation intention, people effectively transfer control of the behaviour to the environment establishing cues to action. For example, by saying that 'When a patient tells me about their low back pain, I will explain the pros and cons of an x-ray to them'. This is a relatively new concept in health behaviour research, however experimental studies suggest that people who have formulated plans like these are more likely to translate their intentions into action than those who have not $[32,33]$. The extent of prior planning will be included as a theoretical construct.

\section{Action theories: self-regulatory model}

In addition to plans and behavioural consequences, it seems likely that the actions that health professionals take may be influenced by their views and feelings about the particular condition that a patient has presented with. Leventhal's self-regulatory model [34] proposes that individuals attempt to make sense of illness by making use of pre-existing knowledge or schemas (cognitive representations), and that these give rise to behavioural responses. For patients, behavioural responses may include going to see a doctor, taking prescribed or non prescribed medicines, participating in rehabilitation programmes etc. For clinicians, responses may include referring a patient for diagnostic tests, prescribing a drug, restoring a carious tooth etc. The model is described as self-regulatory because this is seen as a dynamic process. The aim of the actions that people take is to restore their own (or their patient's) physical or emotional equilibrium. Individuals monitor the success of the strategies they have adopted to cope with the health threat, and persist with those that enable them to solve the problem of what is happening to their health [34]. Such representations have been shown to influence the behaviour of patients, e.g., coping with everyday living [35], taking prescribed medication [36] and attending cardiac rehabilitation programmes [37]. In the proposed project we will investigate whether the cognitive representations that health professionals hold of particular conditions and their emotional reactions to them influence the care that they provide. As far as we are aware, the theory has not been used in this way before.

The individual's own understanding (cognitive representation) of their situation is central to the self-regulatory approach. Leventhal and his colleagues have shown that in relation to illness, this representation has five clear components: these are the perceived identity, cause, controllability, duration and consequences of the condition [34]. These influence how the individual responds to the problem. In addition to coping with their beliefs about the illness, the self-regulatory theory proposes that people actively try to cope with the emotions that are associated with the illness (e.g., fear or distress). These coping responses are also behavioural, and can include a wide range of activities, from information seeking to smoking. It seems likely that health professionals also experience emotional reactions to some conditions or patient groups, for example the emotional reaction to 'heartsink' patients, which may influence their practice. Hence, we will include six theoretical constructs from self-regulatory theory: perceived identity, cause, controllability, duration and consequences of the condition, and emotional reaction to the condition.

\section{Stage theories}

Stage theories propose that behaviour change occurs in a stepwise process, rather than a linear fashion as implied by motivational or action theories. From a stage theory perspective, interventions to facilitate change will be most effective if they are tailored to the stage an individual has reached within this process. Stage theories have been used widely to develop interventions to facilitate changes in behaviours such as smoking cessation (e.g. [38]). While there are differences between the stage models in the number and nature of stages proposed, stage theories typically distinguish motivation and action steps [39-41]. Empirical studies of general population groups have demonstrated that linear or simple two-stage theories (motivation and action) can be as useful as more complex five or seven stage theories for some health-related behaviours [42] and Weinstein et al have demonstrated that different factors influence behaviour at these two stages [43]. Further, in the Precaution Adoption Process model, Weinstein has proposed an additional early stage when individuals may be unaware of the need for behaviour 
change, a stage which may have particular relevance to the early stages of the implementation of evidence [40]. We propose to investigate a four stage model (unaware, unmotivated, motivated but not acting, and taking action) which will be compared with linear theories in order to identify which provides the best rationale for the choice of interventions to change practice.

\section{Work leading up to this study}

The authors have conducted several exploratory studies to investigate the feasibility of using psychological theories in implementation research, and their ability to identify variables that might be prime targets for interventions [20,44-46]. For example, two recent studies have used the theory of planned behaviour to investigate factors associated with prescribing antibiotics for patients with a sore throat amongst general medical practitioners [20], and to investigate the effect of interventions to implement guidelines for the management of third molars among general dental practitioners across Scotland [45]. In both studies, preliminary interviews were used to develop questionnaires following standard procedures for studies using the theory of planned behaviour [47].

In the antibiotics and sore throats study, a postal questionnaire was distributed to a 1 in 2 random sample of GPs in the region, achieving a $70 \%$ response rate. Using the theory, hypotheses were tested about the relationships between GPs' perceptions and the strength of their intention to prescribe antibiotics. This allowed us to do three things. The first was to identify whether GPs intended to prescribe antibiotics or not. The second was to estimate the overall impact of individual beliefs and perceptions on the strength of their motivation to prescribe; in this study, the multiple correlation coefficient between intention to prescribe and the beliefs and perceptions of individual GPs was 0.69 . The third was to identify which beliefs had the biggest impact on motivation. From this, we have made clear predictions about the factors that are likely to increase motivation to reduce prescribing.

The third molar study is a randomised controlled trial, using a $2 \times 2$ factorial design, in which general dental practitioners are randomly allocated to receive audit and feedback or not, and to be given computer-assisted learning or not, following the introduction of guidelines for the management of third molars. A postal questionnaire measuring constructs from the theory of planned behaviour and knowledge of third molar management was distributed to all the participating dentists after the interventions, achieving a response rate of $90 \%$. This has shown that the interventions have different effects on the theoretical constructs. Both of the interventions affected the dentists' intention to follow the guidelines. In addition, computer assisted learning increased their confidence in their ability to put the research evidence into practice (perceived behavioural control), while audit and feedback increased their knowledge of the research evidence. The theory of planned behaviour proposes that changes in practice should follow from effects on perceived behavioural control and intention, but not from effects on knowledge. So, we would expect computer assisted learning should be more effective in this setting than audit and feedback. However we are still collecting the clinical practice outcome data to investigate this.

\section{Aims and objectives of the study}

The aim of this study is to establish a scientific rationale for interventions to translate research findings into clinical practice. We have already identified scientifically validated theories of behaviour that include modifiable determinants of behaviour. The objectives of this study are:

1. To amplify and populate these theories with evidence from the experience of health professionals

2. To use the theories we have identified and the evidence gained in (1) as a basis for developing predictive questionnaires using replicable methods

3. To identify which elements of the questionnaire (i.e., which theoretical constructs) predict clinical practice and distinguish between evidence compliant and non-compliant practice

4. On the basis of these results, to identify variables (based on theoretical constructs) that might be prime targets for interventions.

\section{Methods}

We will conduct seven postal surveys to identify which variables (theoretical constructs) predict practice and identify potential areas for intervention. Four surveys will be focus on general medical practice (two in England and two in Scotland), while three will focus on general dental practice. This will allow us to examine variability due to professional group and health care setting. We have chosen two professional groups working in similar but unrelated primary care settings in order to test the possibility that unchangeable organisational or individual factors moderate the relationship between the included variables and clinical practice. To examine the potential effects of variations in the organisation of primary health care, we will compare GPs practicing in Scotland and the north of England.

\section{Tracer activities and outcome measures}

We will assess compliance with evidence-based recommendations for five tracer activities. In general medical 
Table 2: Criteria for tracer clinical activities

\begin{tabular}{ll}
\hline I & The tracer activity is easy to define \\
2 & The tracer activity relates to morbidity that is amenable to improvement by medical care \\
3 & There is a sound scientific basis for discriminating between good and less than good performance for the tracer activity \\
4 & The effects of non-medical factors on the tracer activity performance should be adequately understood \\
5 & Each tracer activity should yield data on enough patients for valid statistical analysis \\
6 & Together these activities should span the range of morbidity covered by the health care professional \\
7 & Together these activities should span the range of skills required by the health care professionals \\
8 & Together these activities should span the range of resources specified by the health care professionals
\end{tabular}

practice, these will be: norethisterone prescribing for menorrhagia and referrals for lumbar spine x-rays. In general dental practice, these will be: restoration of carious teeth in children, sealants for prevention of caries, and use of $\mathrm{x}$ rays. We have chosen tracer clinical activities based upon the principles of the following criteria derived from Kessner and colleagues [48] and Irvine [49] (Table 2). In addition, we sought tracer activities that are attributable to individual clinicians and where routine data collection systems could provide objective measures of professional performance.

\section{Lumbar spine $x$-ray referrals}

Rationale: Lumbar spine $\mathrm{x}$-rays are of limited diagnostic benefit within primary care settings and are associated with significant ionising radiation dosage [50]. Despite this lumbar spine $\mathrm{x}$-rays are the fourth commonest $\mathrm{x}$-ray request from primary care doctors [51] with referrals continuing at the rate of 7 patients per 1000 patients mean list size per year [52]. We have recently completed a trial that found that appropriate indications for referral were not identifiable by case note review for the majority of GP requests [52]. The trial also observed a reduction in lumbar spine x-rays of $20 \%$ without apparent adverse effects following the introduction of educational messages [52].

Dependent variable: Lumbar spine $\mathrm{x}$-ray requests per 1000 patients per year.

Data sources: We will undertake surveys in geographically distinct areas where general medical practitioners refer to a single radiology department. In addition we will only use departments that have a computerised information system storing details of requesting general practitioner and type of $x$-ray. After obtaining consent from the study practitioners, we will ask the radiology departments to provide data on lumbar spine $\mathrm{x}$-ray requests for three months following the survey. We have successfully used this method in two different studies across six radiological departments [51,52].
Use of norethisterone for management of menorrhagia

Rationale: Norethisterone continues to be used widely in the NHS despite evidence of its limited effectiveness and the availability of effective alternatives [53]. Almost half a million $(497,700)$ prescriptions were issued in the NHS during 2000.

Dependent variable: Prescriptions for norethisterone per 1000 patients per year.

Data sources: After gaining consent from study practitioners, we will request level 4 PACT data and level 2 SPA data on norethisterone prescriptions. We have successfully used this method in a previous study [54].

\section{Use of dental radiographs}

Rationale: intra-oral radiographs have been shown to still produce a clinically significant diagnostic yield and to benefit individual patients by allowing better informed treatment decisions [55]. Although modern intra-oral dental films are associated with very low doses of ionising radiation, the total national "volume" of radiographs taken is such that exposures are kept as low as is reasonably achievable. Within this context and that of the recently published Selection Criteria in Dental Radiography Guideline [55] however, comparison of data from the English and Scottish Dental Practice Boards [56] has shown that dentists in Scotland are taking fewer than optimal intra-oral radiographs.

Dependent variable: number of intraoral radiographs taken per 100 courses of treatment.

Data sources: Detailed, itemised records of all courses of treatment for NHS patients across Scotland are stored in the MIDAS database at the Dental Practice Board in Edinburgh. This audited information is used for paying dentists and is thus subject to rigorous quality assurance measures. 
Use of dental sealants for the prevention of caries in children aged 6-16

Rationale: Dental pit and fissure sealants have been shown to be highly effective in preventing dental caries (decay) in the occlusal (biting) surface of posterior teeth [57]. Increases in the number of sealants in children aged 6-16 with evidence of pre-existing dental caries would be in accordance with the recommendations of a recent SIGN evidence based clinical Guideline [57].

Dependent variable: mean number of sealants per 6-16 year old child.

Data sources: MIDAS database at the Dental Practice Board in Edinburgh - see Descriptive data below.

\section{Restoration of carious teeth in children}

Rationale: In recent years it has become evident that the proportion of teeth with significant dental caries involving the dentine which have received restorations is unacceptably low in both primary and permanent teeth $[58,59]$. Following the recommendations of a recent SIGN evidence based clinical Guideline [57] would result in an increase in the number of carious teeth restored..

Dependent variable: Mean number of restored teeth per 6-16 year old child.

Data sources: MIDAS database at the Dental Practice Board in Edinburgh - see Descriptive data below.

\section{Descriptive data}

In the surveys, we will ask respondents to provide personal and professional details that might influence observed levels of behaviour. From general medical practitioners we will seek details of their practice list size, total number of FTE practitioners and whether they work full time or part time. This will enable us to calculate rates corrected for 1000 patients mean list size. We will also ask about respondent's gender in the norethisterone survey as we anticipate that female practitioners are likely to see more female patients than are male practitioners. We will allow for the effects of gender before fitting the predictor variables derived from the psychological theories.

For the General Dental Practitioners we will follow previously successful strategies in securing agreement from the dentists to let us have access to their "dental practice profiles". These are routinely derived and maintained centrally by the Dental Practice Division in Edinburgh (with whom the Dental Health Services Research Unit has secure data links). Profiles show mean values of treatments per month for each dentist against averages for the local Health Board and Scotland as a whole. We will also collect appropriate personal data about the dentists and compare this with data from the recent national "Toothousand" census of General Dentists in Scotland.

The range of included activities will also allow us to explore contrasts between types of behaviour and professional groups. For example, the use of radiography is common in both general medical and dental practice. In addition we have chosen conditions that are clinically important in their own right, and for which evidencebased advice on best practice is available. In order to identify which variables (theoretical constructs) predict practice across these five tracer activities and to incorporate a geographical comparison in general medical practice seven surveys will be required. These will be of:

- General medical practitioners in Scotland to predict prescribing of norethisterone for menorrhagia

- General medical practitioners in England to predict prescribing of norethisterone for menorrhagia

- General medical practitioners in Scotland to predict referrals for lumbar spine $\mathrm{x}$-rays

- General medical practitioners in England to predict referrals for lumbar spine x-rays

- General dental practitioners in Scotland to predict restoration of carious teeth in children

- General dental practitioners in Scotland to predict the use of sealants for the prevention of dental caries

- General dental practitioners in Scotland to predict the use of dental x-rays

\section{Predictor variables (theoretical constructs)}

In each survey we will test the predictive power of 14 theoretical constructs (predictor variables) drawn from the six theories (Table 1).

\section{Motivational theories: social cognitive theory \\ Theoretical construct: self-efficacy.}

Measures: Two forms of self efficacy have been identified in relation to health behaviours $[22,60]$. One is the extent to which people feel competent in general to control the behaviour in question). The other is the extent to which people feel competent to control their behaviour in specific situations. We will use the English translation of the Generalized Self-Efficacy Scale (GSES)[61] to measure generalised self-efficacy in relation to the five tracer activities. The range of situations in which the tracer activity occurs, and characteristics of the situation that make the practitioner feel more or less able to control their behav- 
iour will be elicited in the interviews. These interview responses will be used to generate situation specific self efficacy items using item types [61].

Number of items: GSES - 10 items; situation specific selfefficacy - 10-15 items.

Response formats: GSES - four choice response (not at all true - exactly true); situation specific self-efficacy - five point Likert type scales.

Scoring: Total score on GSES (range 10-40); total score for situation-specific self efficacy.

Example questions: 'I am certain that I can restore carious teeth in children'; 'I am confident that I can restore a child's carious tooth, even if the child is very anxious.'

\section{Motivational theories: theory of planned behaviour}

Theoretical constructs: behavioural intentions, perceived behavioural control, attitude and subjective norm.

Measures: The strength of behavioural intentions, perceived behavioural control, attitudes towards the behaviour and subjective norms will be assessed using standard item wordings and response formats [47].

Number of items: 3-5 items per construct.

Response formats: 7 point Likert type scales indicating degree of agreement with the item.

Scoring: Mean score for each construct.

Example questions: 'I feel under social pressure to use dental sealants in the next month' (subjective norm), 'I would like to avoid prescribing norethisterone for patients, but I don't really know if I can' (perceived behavioural control). In addition to these four theoretical constructs, we will measure the strength of beliefs underlying attitude, subjective norm and perceived behavioural control, as specified in the theory of planned behaviour.

The three belief based measures will incorporate the beliefs identified in the interviews but will be assessed using standard item formats. For each of these measures there will be 5-6 belief items matched with 5-6 evaluation items (e.g., 'If I refer a patient for a lumbar x-ray they will be reassured' - a behavioural outcome belief, matched with 'Reassuring patients with low back pain is important' - an evaluation of outcome). Each of these items will be measured on 7 point Likert type scales indicating degree of agreement with the item. Belief item scores will be multiplied with evaluation scores and then combined to form the overall scale.

\section{Action theories: operant conditioning}

Theoretical constructs: anticipated consequences of the behaviour; frequency of performing the behaviour in the past.

Measures: The anticipated consequences for the doctor or dentist themselves of performing each tracer activity will be assessed through responses to a series of 'if-then' statements. The range of potential consequences (positive and negative) for each tracer activity will be elicited in the interviews and used to generate items for the questionnaires. The frequency of past behaviour will be assessed by asking the doctor or dentist to estimate how many patients they have seen with tracer condition over a period of time and what proportion they have treated. Number of items: anticipated consequences - 10-15; frequency of past behaviour -2 . Response formats: anticipated consequences - five or seven point Likert type scales indicating degree of agreement with the item; frequency of past behaviour - open questions.

Scoring: anticipated consequences - total score for positive consequences, total score for negative consequences; frequency of past behaviour - proportion of patients treated per number of patients seen in a specified period.

Example questions: Anticipated consequences: 'If I refer a patient for a lumbar spine $\mathrm{x}$-ray, then I will maintain a good relationship with them'; 'If I x-ray a patient's teeth, then the practice will receive a fee'. Frequency of past behaviour: 'Approximately how many patients have you seen with menorrhagia in the last six months?' followed by 'for what proportion of these patients did you prescribe norethisterone?'.

\section{Action theories: implementation intentions}

Theoretical constructs: extent of prior planning.

Measures: To date, most studies of implementation intentions have manipulated them in experimental situations, rather than measured them [32,33]. Hence standard measures of implementation intention have not been developed. We will use one of open questions developed to assess stage of change (see below), but coded to describe the extent of prior planning. Number of items: 12 Response formats: open responses.

Scoring: Responses will be coded by two independent coders into three categories: no evidence of a plan, some evidence of planning, and clearly specified plan.

Example questions: 'if you have thought about changing your practice, what have you decided to do?'; 'how will you go about this?' (please describe) 


\section{Action theories: self-regulatory theory}

Theoretical constructs: Perceived identity, cause, controllability, duration and consequences of the condition; emotional response to the condition (state anxiety).

Measures: Perceived identity, cause, controllability, duration and consequences of the condition will be assessed using questions derived from the Illness Perception Questionnaire [62]. To measure emotional response we will use the state anxiety items from the Spielberger State-Trait Anxiety Inventory [63]. We will preface the items by asking the respondents to think about patients with this condition and to answer the questions according to how they feel about them.

Number of items: cognitive representations - 38 items; emotional response - 20 items.

Response formats: identity - the number of symptoms endorsed as being part of the illness from a list of 15 symptoms (score range 0-15); cause, cure/control, duration, consequences - items rated on five point scales from strongly agree to strongly disagree; state anxiety - four choice response (almost never - almost always).

Scoring: Total score for each of the five dimensions of cognitive representation; total score for state anxiety.

Example questions: 'Menorrhagia is a serious condition' (consequences); 'Norethisterone will be effective in curing menorrhagia' (cure/control); 'Low back pain will last a long time' (duration); 'I feel like a failure' (state anxiety).

\section{Stage of change}

Theoretical construct: stage of change.

Measures: Questions adopting a similar format to those used in studies using the transtheoretical model of behaviour change or the precaution adoption process model $[43,64,65]$.

Number of items: 4-5 questions.

Response formats: yes/no or open response.

Scoring: Responses will be coded by two independent coders into four categories: unaware, unmotivated, motivated but not acting, and taking action.

Example questions: 'Have you heard about the evidence relating to norethisterone and menorrhagia' (no = unaware), 'if you have heard about this evidence, have you ever thought of changing your practice' (no = unmotivated), 'if you have thought about changing your practice, what have you decided to do?' (responses could include deciding that no action is required, or deciding to change practice in some way); 'if you have decided that you need to change your practice, have you done anything about it? (yes = taking action; no = motivated but not acting).

Measures will be developed for each predictor variable for each survey. We will use existing measures as a starting point in this process (wherever possible), and we will follow the standard procedures that have been described to develop measures of these theoretical constructs (e.g. [66]). Initially we will conduct semi-structured interviews with a purposive sample of 10-15 practitioners for each survey. The purpose of these interviews is to identify beliefs and attitudes relevant to the specific tracer activity and its associated health problem. The responses to these questions will be used to generate standard questionnaire items to assess the variables. Each questionnaire will then be piloted for clarity and acceptability to practitioners. The reliability of the measures will be assessed prior to analysis, using Cronbach's alpha to assess internal reliability and confirmatory factor analysis to identify and discard redundant items. The construct validity of the measures will be assessed prior to analysis by examining correlations between predictor variables that are expected to be similar (convergent validity) and dissimilar (discriminant validity). Measures which do not meet minimum criteria for reliability and validity (i.e., $\mathrm{r}<0.7$ ) will not be entered into the analysis.

\section{Sample size and analysis}

The surveys will generate at least ordinal level quantitative data. The relationships between predictor and outcome measures in each survey will be assessed primarily using multiple regression analysis and structural equation modelling - a procedure that utilises the observed covariance matrix. Power calculations for multiple regression analysis depend on the number of cases per predictor variable. A minimum sample size of $50+8 \mathrm{~m}$, where $\mathrm{m}$ is the number of predictor variables, is recommended for testing the multiple correlation, and $104+\mathrm{m}$ for testing individual predictors $[67,68]$. We have 14 predictor variables, requiring a minimum sample size of 162 per survey to test the multiple correlation, or 118 to test individual predictors. We will aim to achieve a final sample size of 200 respondents per survey (1400 respondents in total) to ensure that the sample size is sufficient to take the effects of covariates into account. Sample sizes for multiple regression can also be estimated using the change in $\mathrm{R}^{2}$. Using an $\mathrm{R}^{2}$ of $48 \%$ (as found in our previous work on antibiotic prescribing among GPs [20]), a study using 200 cases will have $90 \%$ power to detect a $3 \%$ increase in the $\mathrm{R}^{2}$ at the 5\% significance level for each additional covariate. Our proposed sample size of 1400 should ensure that the observed covariances are good estimates of the popu- 
lation covariance. An observed correlation of 0.5 will have a standard error of approximately 0.02 .

Two potential sources of response bias could apply in this study: non response to the questionnaire, and non consent to accessing behaviour data. Cummings et al [69] found an average response rate of $61 \%$ in a random sample of studies using surveys mailed to physicians. Recent studies that we have undertaken have suggested that we should achieve at least this response rate. The survey of GPs in Grampian used a questionnaire similar to those in this study, and achieved a response rate of $70 \%$ [20]. Assuming a conservative response rate of $60 \%$ and a total final sample size of 1400 (800 GPs and 600 dentists), we will distribute questionnaires to 334 practitioners per survey (1336 GPs and 1002 dentists). We do not know how many of these practitioners will agree to let us access personal performance data. Sensitivity analyses will be used to assess the possible bias due to non response and non consent.

Logistic and linear multiple regression analysis will be used to assess the overall predictive power of the predictor variables (theoretical constructs) within each survey. Analyses will allow for the impact of two possible confounding variables: the number of patients that could potentially be seen by the GP or dentist (calculated as total practice size divided by the number of partners and adjusted to reflect full-time or part-time work); and the gender of the GP (a potential confound in the survey of norethisterone prescribing). In the final phase of the project, the findings from the seven surveys will be analysed simultaneously adopting a random effects approach [70] to investigate whether the relationships between predictor variables and outcome measures are modified by (a) professional group and (b) geographical location.

\section{Competing interests}

None declared.

\section{Authors' contributions}

All authors contributed to the development of this study. All authors read and approved the final manuscript.

\section{Acknowledgements}

The development of this study was supported by the Medical Research Council Health Services Research Collaboration. It is now supported by a grant from the UK Medical Research Council (G000I325). The Health Services Research Unit and the Dental Health Research Unit are funded by the Chief Scientist Office of the Scottish Executive. Jeremy Grimshaw holds a Canada Research Chair in Health Knowledge Transfer and Uptake. The views expressed in this paper are those of the authors and may not be shared by the funding bodies.

\section{References}

I. Smith WCS, Lee AJ, Crombie IK, Tunstall-Pedoe H: Control of blood pressure in Scotland: the rule of halves. BMJ 1990, 300:98I-3.

2. Eccles $M$, Bradshaw $C$ : Use of secondary prophylaxis against myocardial infarction in the North of England. BMJ I991, 302:91-2.

3. Pendlebury M, Pitts NB, eds: Selection Criteria in Dental Radiography. Faculty of General Dental Practitioners (UK), London 1998.

4. Ketley D, Woods KL: Impact of clinical trials on clinical practice: example of thrombolysis for acute myocardial infarction. Lancet 1993, 342:891-4.

5. Woods KL, Ketley D, Lowy $A$ et al.: Beta-blockers and antithrombotic treatment for secondary prevention after acute myocardial infarction. Eur Heart J 1998, 19:74-9.

6. Department of Health: The new NHS: modern, dependable. London, Department of Health 1997.

7. Eccles MP, Grimshaw JM: Dissemination and implementation of evidence based practice. In Clinical governance in primary care Edited by: van Zwanenberg T, Harrison J. Radcliffe Medical Press, Oxford; 1999.

8. Bero L, Grilli R, Grimshaw JM, Harvey E, Oxman AD, Thomson MA: Closing the gap between research and practice: an overview of systematic reviews of interventions to promote implementation of research findings by health care professionals. BMJ 1998, 3 | 7:465-8.

9. Effective Health Care: Getting evidence into practice. York: NHS Centre for Reviews and Dissemination 1999, 5:1-16.

10. Medical Research Council: A framework for development and evaluation of RCTs for complex interventions to improve health. MRC Health Services and Public Health Board discussion document 2000.

II. Kanfer FH, Goldstein AP, ed: Helping people change: a textbook of methods. New York: Pergamon Press 1986.

12. Walker S: Learning theory and behaviour modification. London: Methuen 1984.

13. Lang PJ, Melamed BJ, Hart J: A psychophysiological analysis of fear modification using an automated desensitisation procedure. J Abnorm Psychol 1970, 76:220-234.

14. Sloane RB, Staples FR, Cristol AH, Yorkston NJ, Whipple K: Psychotherapy versus behaviour therapy. Harvard University Press, Cambridge Massachussets 1975.

15. Shapiro DA, Shapiro D: Meta-analysis of comparative therapy outcome studies: a replication and refinement. Psychol Bull 1982, 92:581-609.

16. Hollon SD, Beck AT: Cognitive and cognitive-behavioural therapies. In Handbook of Psychotherapy and Behaviour Change Volume Fourth edition. Edited by: Bergin A, Garfield S. New York: John Wiley and Sons; 1994:428-466.

17. Ferlie EB, Shortell SM: Improving the quality of health care in the United Kingdom and the United States: A framework for change. Milbank Quarterly 200I, 79:28I-3I5.

18. Thomas RE, Grimshaw JM, Maclennan GS, Fraser C, Matowe L, Eccles M, Shirran L, Wensing M, Dijkstra R, Whitty P, Donaldson C, Hutchison A: A systematic review of the effectiveness of the introduction of clinical guidelines into medical practice. ISQua's 17th International Conference on Quality in Health Care, Dublin 2000.

19. Iles $\mathrm{V}$, Sutherland $\mathrm{K}$ : Organisational change: a review for health care managers and professionals and researchers. London. National Coordinating Centre for NHS Service Delivery and Organisation $R$ \& D 200I.

20. Walker AE, Grimshaw JM, Armstrong E: Salient beliefs and intentions to prescribe antibiotics for patients with a sore throat. British Journal of Health Psychology 200 I, 6:347-60.

21. Abraham C, Sheeran P, Johnston M: From health beliefs to selfregulation: theoretical advances in the psychology of action control. Psychol Health 1999, 13:569-593.

22. Bandura A: Self-efficacy: towards a unifying theory of behaviour change. Psychological Review 1977, 84:191-215.

23. Wallston KA: Hocus-pocus, the focus isn't strictly on locus: Rotter's social learning theory modified for health. Cognitive Therapy and Research 1992, I 6:183-199. 
24. Conner M, Norman P: Health behaviour. In Comprehensive Clinical Psychology Volume 8. Edited by: Johnston DW, Johnston M. Health Psychology. Oxford: Elsevier; 1998: I-38.

25. Ajzen I: The theory of planned behaviour. Organizational Behaviour and Human Decision Processes 1991, 50:179-21 I.

26. Armitage CJ, Conner M: Social cognition models and health behaviour: a structured review. Psychol Health 1999, I5:I-I7.

27. Terry DJ, O'Leary JE: The theory of planned behaviour: the effects of perceived behavioural control and self-efficacy. British Journal of Social Psychology 1995, 34:199-220.

28. Blackman D: Operant conditioning: an experimental analysis of behaviour. London: Methuen 1974.

29. Kanfer FH, Goldstein AP, ed: Helping people change: a textbook of methods. New York: Pergamon Press 1986.

30. Ouellette JA, Wood W: Habit and intention in everyday life: the multiple processes by which past behaviour predicts future behaviour. Psych Bull 1998, I 24:54-74

31. Gollwitzer PM: Goal achievement: the role of intentions. In European Review of Social Psychology Volume 4. Edited by: Stroebe W, Hewstone M. Chichester UK: Wiley; |993:|4|-I85.

32. Orbell S, Hodgkins S, Sheeran P: Implementation intentions and the theory of planned behaviour. Personality and Social Psychology Bulletin 1997, 23:945-954.

33. Gollwitzer PM: The volitional benefits of planning. In The psychology of action: linking cognition and motivation to behaviour Edited by: Gollwitzer PM, Bargh JA. New York: Guilford Press; 1996:287-3I2.

34. Leventhal H, Benyamini $Y$, Brownlee S, Diefenbach S, Leventhal EA, Patrick-Miller P, Robitaille C: Illness perceptions: theoretica foundations. In Perceptions of health and illness Edited by: Petrie KJ, Weinman J. London: Harwood; 1997: 19-46.

35. Earll L, Johnston M, Mitchell E: Coping with motor neurone disease - an analysis using self-regulation theory. Palliat Med 1993 7:21-30.

36. Myers L, Midence K, eds: Adherence to Treatment in Medical conditions. London: Harwood Academic Press 1998.

37. Petrie K, Weinman J, Sharpe N, Buckley J: Role of patients' view of their illness in predicting return to work and functioning after myocardial infarction: longitudinal study. BMJ I996, 3 I 2: II9I-II94.

38. Prochaska J, DiClemente C, Velicer W, Rossi J: Standardized, individualized interactive and personalized self-help programs for smoking cessation. Health Psychol 1993, I 2:399-405.

39. Prochaska J, DiClemente C: Stages and processes of self-change in smoking: Toward an integrative model of change. J Consult Clin Psychol 1 983, 5 I:390-395.

40. Weinstein N: The precaution adoption process. Health Psychol 1988, 7:355-386.

41. Schwarzer R: Self-efficacy in the adoption and maintenance of health behaviours: theoretical approaches and a new model. In Self-efficacy: thought control of action Edited by: Schwarzer R. London: Hemisphere; 1992:217-243.

42. Kraft P, Sutton S, McCreath Reynolds H: The transtheoretical model of behaviour change: are the stages qualitatively different? Psychol Health 1999, I 4:433-450.

43. Weinstein N, Lyon J, Sandman P, Cuite C: Experimental evidence for stages of health behaviour change: the precaution adoption process model applied to home radon testing. Health Psychol 1998, I 7:445-453.

44. Walker AE, Johnston M, Grimshaw JM, Abraham SCS, Campbell MK, and the TEMPEST study group: When do clinicians follow guidelines? Using the theory of planned behaviour to predict intentions to prescribe prophylaxis for patients at risk of deep vein thrombosis [abstract]. J Epidemiol Community Health 1998, 52:676.

45. Bonetti D, Johnston M, Pitts N, Deery C, Ricketts I, Bahrami M, Ramsay $C$, Johnston J: Can psychological models bridge the gap between clinical guidelines and clinicians' behaviour? A randomised controlled trial of an intervention to influence dentists' intention to implement evidence-based practice. Br Dent $J$ in press.

46. Watson MC, Walker AE, Bond CM: Community pharmacists' views and beliefs about the treatment of symptoms suggestive of vaginal thrush in community pharmacies. Pharmacy World \& Science 2000, 22: 130-5.
47. Conner M, Sparks P: The theory of planned behaviour and health behaviours. In Predicting Health Behaviour Edited by: Conner M, Norman P. Buckingham: Open University Press; 1996:121-162.

48. Kessner DM, Kalk CE, Singer AA: Assessing health quality - the case for tracers. $N$ Engl J Med 1973, 288: I89-194.

49. Irvine $D$ : Managing for quality in general practice (Medical Audit Series 2). London: King's Fund 1990.

50. Royal College of Radiologists: Making the best use of a department of Radiology. Guidelines for doctors. London: RCR I998.

51. Matowe L: An evaluation of the use of time series analysis designs in clinical guidelines implementation studies. $P h D$ Thesis. University of Aberdeen: Health Services Research Unit 200I.

52. Eccles MP, Steen IN, Grimshaw JM, Thomas L, McNamee P, Souter J, Wilsdon J, Matowe L, Needham G, Gilbert F, Bond S: Effect of audit and feedback, and reminder messages on primary-care referrals: a randomised trial. Lancet 200I, 357:|406-09.

53. Effective Health Care: The management of menorrhagia. York: NHS Centre for Reviews and Dissemination 1995, 9:1-14.

54. Hall L, Eccles M, Barton R, Steen N, Campbell M: Is untargeted outreach visiting in primary care effective? A pragmatic randomised controlled trial. J Pub Health Med 2001, 23(2): I09-II3.

55. Pendlebury $M$, Pitts NB, Eds: Selection Criteria in Dental Radiography. Faculty of General Dental Practitioners (UK), London 1998.

56. Pitts NB, Fyffe HE: Scottish dentists' use of and opinions regarding bitewing adiography. Dentomaxillofac Radiol 1991, 20:214-218

57. SIGN Guideline: Targeted Caries Prevention in 6- 16 year olds Attending for Dental Care. Scottish Inter-Collegiate Guideline Network, Edinburgh 2000.

58. Pitts NB, Evans DJ, Nugent ZJ: The dental caries experience of 5 year old children in Great Britain. Surveys coordinated by the British Association for the Study of Community Dentistry in 1999/2000. Community Dent Health 200I, I 8:49-55.

59. Pitts NB, Evans DJ, Nugent ZJ: The dental caries experience of I 4-year old children in the United Kingdom. Surveys coordinated by the British Association for the Study of Community Dentistry in 1998/99. Community Dent Health 2000, I 7:48-53.

60. Schwarzer R, Ed: Self-efficacy: thought control of action. Washington DC: Hemisphere 1992.

61. Johnston M, Wright S, Weinman J: Measures in health psychology: a users portfolio. Oxford: NFER-Nelson 1995.

62. Weinman J, Petrie KJ, Moss-Morris R, Horne R: The illness perception questionnaire: a new method for assessing the cognitive representation of illness. Psychol Health I I:43 | -446.

63. Spielberger CD, Gorsuch RL, Luchene RE: Manual for the StateTrait Anxiety Inventory (revised edition). Palo Alto CA: Consulting Psychologists Press 1983.

64. Weinstein ND, Rothman A, Sutton SR: Stage theories of health behaviour: conceptual and methodological issues. Health Psychol 1998, I 7:290-299.

65. DiClemente CC, Prochaska JO, Fairhurst SK, Velicer WF, Velasquez MM, Rossi JS: The process of smoking cessation: an analysis of precontemplation, contemplation and preparation stages of change. J Consult Clin Psychol I 991, 59:295-304.

66. Conner M, Norman P, Eds: Predicting Health Behaviour. Buckingham: Open University Press 1996.

67. Tabachnik BG, Fidell LS: Using multivariate statistics. New York: HarperCollins 1996:132-I33.

68. Green SB: How may subjects does it take to do a regression analysis? Multivariate Behavioural Research 1991, 26:499-510.

69. Cummings SM, Savitz LA, Konrad TR: Reported response rates to mailed physician questionnaires. Health Serv Res 2001, 35: I347-1355.

70. Aitkin M: Meta-analysis by random effect modelling in generalized linear models. Stat Med 1999, I 8:2343-235 I.

\section{Pre-publication history}

The pre-publication history for this paper can be accessed here:

http://www.biomedcentral.com/1472-6963/3/22/prepub 